\title{
BMJ Open Medication incidents in primary care medicine: protocol of a study by the Swiss Federal Sentinel Reporting System
}

\author{
Markus Gnädinger, ${ }^{1}$ Alessandro Ceschi, ${ }^{2,3}$ Dieter Conen, ${ }^{4}$ Lilli Herzig, ${ }^{5}$ \\ Milo Puhan, ${ }^{6}$ Alfred Staehelin, ${ }^{1,7}$ Marco Zoller $^{1}$
}

To cite: Gnädinger $\mathrm{M}$, Ceschi A, Conen D, et al. Medication incidents in primary care medicine: protocol of a study by the Swiss Federal Sentinel Reporting System. BMJ Open 2015;5:e007773.

doi:10.1136/bmjopen-2015007773

- Prepublication history and additional material is available. To view please visit the journal (http://dx.doi.org/ 10.1136/bmjopen-2015007773)

Received 26 January 2015 Revised 13 March 2015 Accepted 18 March 2015

CrossMark

For numbered affiliations see end of article.

Correspondence to Dr Markus Gnädinger; markus.gnaedinger@hin.ch

\section{ABSTRACT}

Background/rationale: Patient safety is a major concern in healthcare systems worldwide. Although most safety research has been conducted in the inpatient setting, evidence indicates that medical errors and adverse events are a threat to patients in the primary care setting as well. Since information about the frequency and outcomes of safety incidents in primary care is required, the goals of this study are to describe the type, frequency, seasonal and regional distribution of medication incidents in primary care in Switzerland and to elucidate possible risk factors for medication incidents.

Methods and analysis: Study design and setting: We will conduct a prospective surveillance study to identify cases of medication incidents among primary care patients in Switzerland over the course of the year 2015. Participants: Patients undergoing drug treatment by 167 general practitioners or paediatricians reporting to the Swiss Federal Sentinel Reporting System. Inclusion criteria: Any erroneous event, as defined by the physician, related to the medication process and interfering with normal treatment course. Exclusion criteria: Lack of treatment effect, adverse drug reactions or drug-drug or drug-disease interactions without detectable treatment error. Primary outcome: Medication incidents. Risk factors: Age, gender, polymedication, morbidity, care dependency, hospitalisation. Statistical Analysis: Descriptive statistics to assess type, frequency, seasonal and regional distribution of medication incidents and logistic regression to assess their association with potential risk factors. Estimated sample size: 500 medication incidents. Limitations: We will take into account under-reporting and selective reporting among others as potential sources of bias or imprecision when interpreting the results.

Ethics and dissemination: No formal request was necessary because of fully anonymised data. The results will be published in a peer-reviewed journal.

Trial registration number: NCT0229537.

\section{INTRODUCTION}

Patient safety is a major concern in healthcare systems worldwide. Although most safety research has been conducted in the inpatient

\section{Strengths and limitations of this study}

- First Swiss prospective and systematic collection of incident data in primary care.

- Covering three linguistic regions and two distribution systems.

- Bias from selective and under-reporting or non-detection.

setting, ${ }^{1}$ evidence indicates that medical errors and adverse events pose a serious threat for patients in the primary care setting as well, since most patients receive ambulatory care. ${ }^{2-4}$ Gandhi and Lee ${ }^{5}$ noted that safety concerns in the outpatient setting differ from those in the hospital setting in obvious and non-obvious ways. Medication-related incidents are also important in primary care, but are perhaps not as well documented as in secondary care. A study by Gandhi and Lee ${ }^{6}$ in primary care showed that $25 \%$ of 661 ambulatory care patients with at least one prescription had such an incident, of which $13 \%$ were classified as serious and $39 \%$ as preventable or ameliorable. In a study by Pirmohamed et al in the UK, medication-related incidents caused about $6.8 \%$ of all hospitalisations ${ }^{7}$ and in Switzerland, these incidents are responsible for about $7.2 \%$ of hospitalisations. ${ }^{8}$ Diagnostic errors ${ }^{9}$ and adverse drug events have been identified as frequent safety concerns; furthermore, there is a body of literature about the safety of outpatient procedures and the consequences of coordination as well as continuity-of-care failures. ${ }^{10}$ Hospital and outpatient care also differ in their infrastructure and in many processes, as well as in their ability to detect, monitor and address safety issues. Information about the frequency and outcomes of safety incidents in primary care is required to identify risks or 'hot spots', to prioritise them and to take action as needed. 


\section{Definition of terms}

For the purpose of our study, we use the terminology of the International Classification for Patient Safety (WHO). ${ }^{11}$ Here, a patient safety incident is defined as an event or a circumstance which could have resulted or did result in unnecessary harm to a patient. There are several possible causes. (1) An error, defined as: failure to carry out a planned action as intended or an application of an incorrect rule; (2) A violation, defined as: deliberate deviation from an operating procedure, standard or rule; (3) An (external) circumstance, defined as: a situation or factor that may influence an event, agent or person. We want to distinguish incidents from adverse drug reactions (ADR) which are defined as: unexpected harm resulting from a justified action where the correct medication process was followed for the context in which the event occurred. The same applies to drug-drug or drug-disease interactions (DDI). Critical Incident Reporting System (CIRS) refers to a voluntary anonymous database system to which Swiss family physicians or paediatricians may report incidents as those occurred in their practices.

We will restrict the topic of our study to medicationrelated incidents. Medication or medicine refers to a pharmaceutical drug, officially called a medicinal product, which can be loosely defined as any chemical substance-or product comprising such-intended for use in the medical diagnosis, cure, symptomatic treatment, or prevention of disease (Wikipedia).

\section{Information retrieval}

Methods to collect information about adverse incidents are manifold. ${ }^{2}{ }^{11-14}$ In the literature, different ways to collect adverse incident information are described: voluntary versus mandatory reporting systems, patient questionnaires, or pharmacists reporting to registries. Interviews can be held with physicians or questionnaires can be filled out by them. Charts of deceased patients can be audited meticulously or medicolegal cases may be analysed. Information may be derived prospectively in an actual case by case manner or retrospectively along case vignettes. The two methods most commonly used are incident reporting and chart review. Both methods have the potential to systematically cover information on the entire range of safety events in medical offices in common.

Incident reporting has a long tradition in clinical risk management and is increasingly used in outpatient care. ${ }^{15-18}$ Indeed, incident reporting has been the dominant method for the study of safety incidents in primary care. ${ }^{19}$ It is based on voluntary and usually anonymous reports of physicians and nurses, and is used to describe the types and characteristics of patient safety incidents. These reports may vary considerably with respect to the information which is included and the likelihood of 'true' incidents being reported is unclear. Studies based on this method describe large variations in the number of reports submitted..$^{20}$ Moreover, professional groups differ in their frequency of reporting; in-hospital care physicians reported preferentially severe incidents, while nurses cover the whole spectrum of impact levels. ${ }^{20}$ Selective reporting by physicians may have multifactorial causes such as lack of time, thinking that an ADR which is already known is not worth mentioning, or concerns about data confidentiality. Non-reporting may be as frequent as $94 \% .^{21}{ }^{22}$ O'Beirne et al concluded from a very low report rate $(<1$ report per person per year) that incident reporting may be "a costly but not very effective way to study safety problems in primary care". ${ }^{23}$ A recent Swiss study analysed safety issues in primary care. ${ }^{12}$ This was a semiquantitative, retrospective investigation involving over 300 nurses and physicians. Seven of 23 issues were related to drug treatment. Frequently named issues were insufficient monitoring of potential side effects, missing prescriptions of required treatment, and errant medication relating to the route of administration, dosage or timing. The low and perhaps, selective reporting of incidents in any system makes it difficult or virtually impossible to collect valuable quantitative information from CIRS. ${ }^{24}$

In chart review, medical records are analysed by independent experts in order to identify adverse events, and to assess potential harm and preventability in each case. $^{25}$ Such analysis requires complete and correct patient documentation to provide valid results. In many cases relevant information may be unavailable. ${ }^{25}$ As chart review is a time-consuming approach, many resources are needed to analyse a large number of patient records at different primary care offices; furthermore, this kind of analysis is usually retrospective.

Sandars and Esmail ${ }^{2}$ described a frequency of 5-80 medical errors per 100000 consultations in primary care patients. Incidents, as defined above, may also result from circumstantial factors (without any errors) and therefore, occur somewhat more frequently. In order to not overburden the participating physicians with our study, we decided to limit our focus to medication incidents. These make up between $9 \%$ and $42 \%$ of all registered incidents $^{2}{ }^{9} 26-28$ and of these, approximately $70 \%$ may be prescription errors. ${ }^{29}$ In contrast to the study by Sandars and Esmail, our pilot study found a rate of approximately one medication incident per 2 months and per physician (see online supplementary appendix 1), while the former reported a rate of about one in 2 years.

Concerning predisposing factors, Avery et $a l^{30}$ found a propensity for becoming a victim of medication errors with the young $(<15$ years) or elderly ( $>64$ years) ages. The latter was confirmed by Salanitro $e t a l .{ }^{31}$ Two studies by Field et $a \hat{l}^{2} 33$ reported morbidity as promoting errors. All studies listed polymedication as a key factor. ${ }^{30-34}$ Better knowledge of factors associated with medication errors would be helpful to implement preventive measures and therefore, reduce the frequency of avoidable incidents in the future.

\section{The Swiss National Sentinel Reporting Network (http://www.sentinella.ch)}

To apply a supplementary method to gaining insight into safety hot spots in primary care, we aim to assess 
medication errors by using the Swiss National Sentinel Reporting Network. Founded in 1986, it was mainly designed to survey transmissible diseases. Later, it also assessed other health problems of public interest. In 2015, besides our project, the areas covered are: surveillance of mumps, whooping cough, flu or Borrelia, pneumonia and middle ear infections, tick bites, vaccinations against measles or whooping cough, and alcohol use among adolescents. One hundred and forty general internal medicines and 27 paediatric practices report to the system, 109 of them in the German, 44 in the French, and 14 in the Italian part of Switzerland. It generates daily to weekly current data and covers the entire geographic and linguistic regions of our country.

\section{METHOD}

\section{Aims of the project}

To describe the type, frequency, seasonal and regional distribution of medication incidents in primary care in Switzerland and to elucidate possible risk factors such as age, gender, polymedication, morbidity, and previous hospitalisation.

\section{Study design}

We will conduct a prospective surveillance study to identify cases of medication incidents among primary care patients over the course of 1 year.

\section{Population}

Any person undergoing drug treatment in general internal or paediatric practices participating in the Sentinella network. The latter covers a representative sample of patients in primary care for Switzerland (see above). These patients include children, individuals with mental retardation or the elderly-all of whom might be at increased risk for medication errors.

\section{Inclusion criteria}

- Any erroneous event (as defined by the physician) relating to the medication process and interfering with the normal treatment course.

\section{Exclusion criteria}

- Lacking treatment effect, ADR, or drug-drug interaction or DDI without detectable treatment error.

- Refusal of patients to refer data to the Sentinel system.

\section{Questionnaire development}

As we could not identify questionnaires suitable for continuous reporting and adaptable to our local conditions, we had to develop new ones. We tested these in an 8-week pilot study (see online supplementary appendix 1).

In the Sentinella study, the Italian speaking physicians had to decide whether to report in German or French. For the main study, we developed only two language sets of questionnaires, since these had to be filled in only by physicians, not by patients. We deemed assessment of construct validity of the questionnaires not imperative, since we did not measure hidden constructs (like 'depression') by our questions and information was mainly needed about influencing our target variable, that is, the type and frequency of incidents.

\section{Data to be collected}

The data to be collected in our study are summarised in boxes 1 (physician related) and 2 (patient related/incident related); for the latter, only pre-existing data from medical records will be collected. Furthermore, we collected denominator data as depicted in box 3 .

\section{Time schedule}

The pilot study took place from July until September 2013. The final questionnaires in both languages and their English translation are available at http://www. medication-incidents.ch. The main study takes place from January until December 2015. Evaluation of the study data and writing of the publication will be performed in 2016 .

\section{Statistics}

\section{Expected number of cases}

On the basis of our pilot trial (see online supplementary appendix), we expect at least one drug-related incident to be reported every 2 months per physician. In the Sentinella system, there are currently 167 physicians actively reporting, among them are 27 paediatricians.

\section{Box 1 Physician-related data}

Initial questionnaire

Sentinella identification number

Gender*

Age * $^{*}$

Specialisation (general practitioner or paediatrician)*

Number of physicians in practice, and among them those reporting to Sentinella*

Working hours per week*

Drug distribution system (by pharmacist or by physician)

Drug prescription system (electronic, machine written, hand-written)

Electronic drug-drug interaction (DDI) system

Availability of X-ray, ECG, ultrasound

Medical history (electronic or paper based)

Quality certificate

Team sessions

Physician's participation in quality circle

Localisation (urbanity, language region)*

Special education/interests

Caring for institutions

Final questionnaire

Proportion of non-reporting incidents during the study

The data are collected from each physician reporting to the Sentinella system. The questionnaire and the coding plan are available at http://www.medication-incidents.ch.

*These data is delivered by Sentinella administration. All other data will be collected by use of questionnaires. 


\title{
Box 2 Patient-related data
}

\author{
Patient-related/incident-related items \\ Week of reporting \\ Year of birth \\ Gender \\ Physician-to-patient relationship \\ Dwelling situation \\ Social problems \\ Dementia or learning disabilities \\ Psychiatric problems \\ Use of psychotropic drugs \\ Linguistic problems \\ Smoking or substance abuse \\ Visual blurring or hearing loss \\ Gait disturbance \\ Renal insufficiency \\ Liver cirrhosis/insufficiency \\ Previous hospitalisation (12 months) \\ Care dependency \\ Number of chronically administered active drugs* \\ Number of diagnoses for chronic disease \\ Scale value of 'Thurgau Morbidity Index' (TMI) ${ }^{35}$ \\ Description of incident \\ Who noticed the incident \\ What went wrong \\ Name of drug \\ Other drugs used possibly related to the incident \\ Endangering of patient \\ Amount of damage \\ Organ system involved \\ Duration \\ Recovery \\ Treatment/surveillance \\ Causal triggers \\ Interface problems \\ Information to the patient about the incident and his reaction \\ Consequences of the incident \\ Responsibility \\ Possibility to anticipate the incident \\ Whether a similar incident was previously notified within the study \\ General proposals \\ Physician-related items \\ Sentinella identification number
}

The data are collected for each incident. The basic reporting of a medication incident is collected weekly. It includes the Sentinella identification number, the gender of the patients and their year of birth. The questionnaire and the coding plan are available at http://www. medication-incidents.ch.

${ }^{\star}$ Each regularly prescribed or administered pharmacological specialty counts per active substance contained, according to the latest available medication list. All therapies regularly taken during at least 1 month are considered. Drugs that are prescribed for shorter periods (eg, antibiotics for a week) are not included. Regularly administered eye drops, inhalations, nasal sprays count if a general systemic effect is intentional (eg, calcitonin nasal spray) or must be taken into account (eg, timolol eye drops). Also transcutaneous, subcutaneous or vaginal hormone-releasing systems, and preparations administered by the specialist (eg, gynecologist: birth control pills) should be recorded. Herbal drugs count-regardless of the number of plants-as one medication. Homeopathic drugs, cell salts, etc, are not counted. Multivitamins count if they are taken due to a medical indication (eg, short bowel syndrome), but not when the administration was adopted as 'roborant'; multivitamins are considered one drug. Also therapies at the hospital administered such as oncology are counted. Whether the patient also applies the drug (compliance) is irrelevant to the study, the important thing is that it is so prescribed. Prescribed medications to relieve on requirement which do not need to be taken daily, or self-medication is not recorded.

When assuming that they work 10 months per year, this would result in 660 reported incidents. We, hence, have to decrease this number to some extent because not all physicians work $100 \%$, there will be some non-reporting or non-detection of incidents, and paediatricians report lower rate of incidents (according to the results of our 


\section{Box 3 Denominator data}

Fortnight analysis (only once in study, from 7 to 20 March 2015)

Previous hospitalisation (during the preceding year)

Care dependency

Number of active drugs chronically administered

Number of chronic diagnoses

Scale value of 'Thurgau Morbidity Index' (TMI) ${ }^{35}$

Year of birth*

Gender*

Multiple consultation (within the 14-day period)

Sentinella identification number

Daily analysis

Physician-to-patient contacts

Sentinella identification number

The data are collected from each patient consulting the practice during the year 2015, irrespective of the presence of an incident.

*Year of birth and gender will be collected during another 14-day period in fall but without the other items. The questionnaire and the coding plan are available at http://www.medication-incidents. ch. Definition of medication count: see box 2.

pilot study). So we expect approximately 500 incidents in our study.

\section{Statistical methods}

For the analysis of our data, we will use descriptive statistics in order to describe the type, frequency, seasonal and regional distribution of medication incidents. We will use logistic regression to assess the association of medication incidents with potential risk factors. We will use SPSS.

\section{Independent ethical committee}

The ethical committee of Canton Zurich decided that our study did not need formal approval, because the data are completely anonymous (KEK-ZH 2014-0400). The study was recorded in http://www.ClinicalTrials.gov: NCT02295371, as well as in our national study registry (http://www.kofam.ch; SNCTP000001207).

STROBE statement: Where applicable, our publication will follow the general STROBE guidelines (http://www. equator-network.org/).

\section{RESULTS FROM A PILOT STUDY}

From the existing literature, ${ }^{12}$ we included questions on the social and clinical state of the patients, on the type of incident, and on possible causative factors, and tested these in a pilot study, from July until September 2013, with a sample of general physicians or paediatricians; these were in two language sets (German and French) for the three different language regions of Switzerland (German 11, French 7, Italian 3) for 8 weeks. Fifty-one cases were recorded, leading to an incident rate of 0.4 (median, IQR 0.4 ) per family physician, and week or 4 (5) per family physician and 1000 patient contacts. Virtually no incidents were observed by paediatricians (details of this study are presented in online supplementary appendix 1).

\section{DISCUSSION}

\section{Strength and limitations}

Our study is the first prospective and systematic collection of incident data in Swiss primary care. The wellmotivated reporting physicians, the duration of 12 months and the coverage of the three main linguistic regions as well as of two drug distribution systems will deliver new and relevant insights.

Not all cases may be reported; there may be some selective reporting of cases of higher clinical importance, and some cases may not be reported due to lack of time or legal considerations. Some cases may not be detected by the physicians. Some non-prescription treatments may be missed if they are not causally linked to the incident. The sample size may be too small for inferential statistics. The 14-day denominator period may not be representative for the patient collective over the whole year. The definition of inclusion criteria may be interpreted varyingly by the physicians. Qualitative information may be missed in this study and has perhaps to be further addressed in qualitative research. The low and perhaps selective reporting of incidents in any system makes it difficult or virtually impossible to collect valuable quantitative information from CIRS. ${ }^{24}$

\section{CONCLUSION}

Data on safety issues in ambulatory primary care patients is scarce and this is also true for Switzerland. The retrospective qualitative study by Gehring et $a l^{12}$ and the study by Livio et $a \ell^{8}$ on hospitalisations makes it reasonably clear that things are in no way better than that in $\mathrm{UK}^{7}$ or USA, ${ }^{6}$ where $6.5 \%$ of all hospitalisations and $4.0 \%$ of all hospital care days as well as 1 in 667 hospital deaths are caused by medication incidents. Since up to $72 \%$ of these appear to be preventable or ameliorable, it seems worthwhile to focus on these so as to further elucidate risk factors.

The data of our study should allow for describing the type, frequency, seasonal and regional distribution of medication incidents in Swiss primary care practices and for helping to identify risk factors. The definition of 'hot spots' could sensitise the physicians to focus on dangerous situations and help them to redefine their standing operational procedures (SOPs).

\section{Author affiliations}

${ }^{1}$ Institute of Primary Care, University of Zurich, Zurich, Switzerland

${ }^{2}$ Department of Clinical Pharmacology and Toxicology, University Hospital Zurich, Zürich, Switzerland

${ }^{3}$ National Poisons Centre, Tox Info Suisse, Associated Institute of the

University of Zurich, University Hospital Zurich, Zürich, Switzerland

${ }^{4}$ Patientensicherheit Schweiz, Zürich, UK

${ }^{5}$ Policlinique Médicale, University of Lausanne, Lausanne, UK

${ }^{6}$ Epidemiology, Biostatistics, and Prevention Institute, University of Zurich, Zürich, Switzerland

${ }^{7}$ Sentinel Surveillance Network, Swiss Federal Office of Public Health, Bern, Switzerland

Acknowledgements The authors are grateful to Lee Wennerberg for English language corrections, the Federal Health Agency for the translation of their 
pilot study questionnaires into French, Dr Sven Staender, Männedorf, for the helpful comments. They thank all colleagues participating in the pilot study (Banderet HR, Bigler M, Dafflon M, Ebnöther S, Ferrazzini G, Frey J, Fröhlich F, Haftgoli N, Köhler B, Marty F, Mühlemann N, Merz A, Oppliger S, Pasche 0 , Pilet F, Quack C, Sébo P, Schwarzenbach HR, Spirig M, Valentin J).

Contributors MG lead the study, did the pilot study (questionnaire development, data entering and processing), wrote all documents, made all the contacts with the Sentinella administration, ethics committee and others, programmed the electronic questionnaires, will enter the hand-written questionnaires into the database, will do the data processing and will write the publication after data collection. LH is French speaking and will help others to understand the French-printed questionnaires. MP was responsible for sound methodology. AS conceived the idea for the study. All the authors have seen all the study documents and contributed intellectually to this publication. All the authors have contributed to the revision of the draft of this publication, and approved the submitted version of this publication.

Funding The study was funded by Bangeter-Rhyner Foundation, Basel (grant number 8472/HEG-DSV).

Competing interests None declared.

Provenance and peer review Not commissioned; externally peer reviewed.

Open Access This is an Open Access article distributed in accordance with the Creative Commons Attribution Non Commercial (CC BY-NC 4.0) license, which permits others to distribute, remix, adapt, build upon this work noncommercially, and license their derivative works on different terms, provided the original work is properly cited and the use is non-commercial. See: http:// creativecommons.org/licenses/by-nc/4.0/

\section{REFERENCES}

1. Manias E. Detection of medication-related problems in hospital practice: a review. Br J Clin Pharmacol 2012;76:7-20.

2. Sandars J, Esmail A. The frequency and nature of medical error in primary care: understanding the diversity across studies. Fam Pract 2003;20:231-6.

3. Thomsen LA, Winterstein AG, Søndergaard B, et al. Systematic review of the incidence and characteristics of preventable adverse drug events in ambulatory care. Ann Pharmacother 2007:41:1411-26.

4. Miller GC, Britth HC, Valenti L. Adverse drug events in general practice patients in Australia. Med J Aust. 2006;184:321-4.

5. Gandhi TK, Lee TH. Patient safety beyond the hospital. $N$ Engl J Med 2010;363:1001-3.

6. Gandhi TK, Weingart SN, Borus J, et al. Adverse drug events in ambulatory care. N Engl J Med 2003;348:1556-64.

7. Pirmohamed M, James S, Meakin S, et al. Adverse drug reactions as cause of admission to hospital: prospective analysis of 18820 patients. BMJ 2004;329:15-19.

8. Livio F, Buclin T, Yersin B, et al. Hospitalisations pour effet indésirable médicamenteux: Recensement prospectif dans un service d'urgences médicales. Lausanne: Institut Universitaire de Médecine Sociale et Préventive, 1998 (Raisons de Santé, 23).

9. Schiff GD, Hasan O, Kim S, et al. Diagnostic error in medicine. Arch Intern Med 2009;169:1881-7.

10. Fröhlich $\mathrm{T}$, Zorina $\mathrm{O}$, Fontana $\mathrm{AO}$, et al. Evaluation of medication safety in the discharge medication of 509 surgical inpatients using electronic prescription support software and an extended operational interaction classification. Eur J Clin Pharmacol 2011;67:1273-82

11. Runciman $\mathrm{W}$, Hibbert $\mathrm{P}$, Thomson $\mathrm{R}$, et al. Towards an international classification for patient safety: key concepts and terms. Int J Qual Health Care 2009;21:18-26.

12. Gehring $\mathrm{K}$, Schwappach DL, Battaglia M, et al. Frequency of and harm associated with primary care safety incidents. Am J Manag Care 2012;18:e323-37
13. Wetzels R, Wolters $\mathrm{R}$, van Weel $\mathrm{C}$, et al. Mix of methods is needed to identify adverse events in general practice: a prospective observational study. BMC Fam Pract 2008;9:35.

14. Gaal S, Harman C, Giesen $P$, et al. Complaints against family physicians submitted to disciplinary tribunals in the Netherlands: lessons for patient safety. Ann Fam Med 2011:9:522-7.

15. Rubin G, George A, Chinn DJ, et al. Errors in general practice: development of an error classification and pilot study of a method for detecting errors. Qual Saf Health Care 2003;12:443-7.

16. Elder NC, Vonder Meulen M, Cassedy A. The identification of medical errors by family physicians during outpatient visits. Ann Fam Med 2004;2:125-9.

17. Makeham MA, Kidd MR, Saltman DC, et al. The Threats to Australian Patient Safety (TAPS) study: incidence of reported errors in general practice. Med J Aust 2006;185:95-8.

18. Makeham MA, Dovey S, Runciman WB, et al. Methods and measures used in primary care patient safety research. Geneva, Switzerland: World Health Organization, 2008.

19. Makeham MA, Dovey SM, County M, et al. An international taxonomy for errors in general practice: a pilot study. Med $J$ Aust 2002;177:68-72.

20. Rowin EJ, Lucier D, Pauker SG, et al. Does error and adverse event reporting by physicians and nurses differ? Jt Comm J Qual Patient Saf 2008;34:537-45.

21. Hazell L, Shakir SA. Under reporting of adverse drug reactions: a systematic review. Drug Saf 2006;29:385-96.

22. Gnädinger M, Mellinghoff HU. The out-of-focus bias in drug surveillance. Eur J Clin Pharmacol 2013;69:357-9.

23. O'Beirne M, Sterling PD, Zwicker K, et al. Safety incidents in family medicine. BMJ Qual Saf 2011;20:1005-10.

24. Pham JC, Girard T, Pronovost PJ. What to do with healthcare incident reporting systems? J Public Health Res 2013 2:e27.

25. Stange KC, Zyzanski SJ, Smith TF, et al. How valid are medical records and patient questionnaires for physician profiling and health services research? A comparison with direct observation of patient visits. Med Care 1998;36:851-67.

26. Gaal S, Verstappen W, Wolters R, et al. Prevalence and consequences of patient safety incidents in general practice in the Netherland: a retrospective medical record review study. Implement Sci 2011;6:37.

27. Wetzels R, Wolters R, van Weel C, et al. Harm caused by adverse events in primary care: a clinical observational study. J Eval Clin Pract 2009;15:323-7.

28. Khoo EM, Lee WK, Saraks $\mathrm{S}$, et al. Medical errors in primary care clinics-a cross sectional study. BMC Fam Pract 2012;13:127.

29. Kuo GM, Phillips RL, Graham D, et al. Medication errors reported by US family physicians and their office staff. Qual Saf Health Care 2008;17:286-90.

30. Avery AJ, Maisoon G, Barber N, et al. The prevalence and nature of prescribing and monitoring errors in English general practice: a retrospective case note review. Br J Gen Pract 2013;63. e534-53.

31. Salanitro AH, Osborn CY, Schnipper JL, et al. Effect of patient- and medication-related factors on inpatient medication reconciliation errors. J Gen Intern Med 2012;27:924-32.

32. Field TS, Gurwitz JH, Harrold LR, et al. Risk factors for adverse drug events among older adults in the ambulatory setting. J Am Geriatr Soc 2004:52:1349-54.

33. Field TS, Mazor KM, Briesacher B, et al. Adverse drug events resulting from patient errors in older adults. J Am Geriatr Soc 2007:55:271-6

34. Mira JJ, Orozco-Beltran D, Perez-Jover V, et al. Physician patient communication failure facilitates medication errors in older polymedicated patients with multiple comorbidities. Fam Pract 2013;30:56-63.

35. Fischer JE, Peltenburg M, Kühne R, et al. Der TMI auf dem Prüfstand: Güte und Probleme der Kostenvorhersage anhand einfach kodierbarer Patientenmorbidität. Schweizerische Ärztezeitung 2007;88:1156-65. 